Original Research Article

\title{
Attenuation of stress response to laryngoscopy and intubation: sublingual nitroglycerin spray vs intravenous fentanyl and sublingual nitroglycerin spray
}

\author{
Binod Pegu*, Suneeta Dutta, Deba Gopal Pathak, Kamal Chandra Deori
}

Department of Anaesthesiology, Silchar Medical College,

Silchar, Assam, India

Received: 25 March 2017

Revised: 24 April 2017

Accepted: 27 April 2017

*Correspondence to:

Dr. Binod Pegu,

Email: binodpegu10@

gmail.com

Copyright: () the author(s), publisher and licensee Medip Academy. This is an openaccess article distributed under the terms of the Creative Commons Attribution NonCommercial License, which permits unrestricted noncommercial use, distribution, and reproduction in any medium, provided the original work is properly cited.

\begin{abstract}
Background: Laryngoscopy and tracheal intubation is invariably associated with certain cardiovascular changes such as tachycardia, rise in blood pressure and a wide variety of cardiac arrhythmias. 1 Such complications are highly detrimental in patients with limited cardiovascular reserve specially in geriatric and elderly population. Various pharmacological agents have been used to attenuate these stress responses but none has yet been considered ideal. Therefore, purpose of this study is to investigate the efficacy of sublingual Nitroglycerine spray alone and sublingual Nitroglycerine spray with intravenous Fentanyl to attenuate the pressor response to laryngoscopy and intubation in normotensive patients.

Methods: A total of 120 ASA I and II patients of age group 18-60 years scheduled for elective surgical procedure under general anesthesia were randomly divided into 3 groups of 40 in each group. Group 1 control group, Group 2, received NTG sub-lingual spray $(0.4 \mathrm{mg} / \mathrm{spray})$ two $\mathrm{min}$. before induction, and Group 3 received inj. Fentanyl $(2 \mu \mathrm{g} / \mathrm{kg}) 5 \mathrm{~min}$ before + NTG sublingual spray ( $0.4 \mathrm{mg} / \mathrm{spray}) 2 \mathrm{~min}$ before induction. Vital parameters before and after induction and thereafter at specified time interval following laryngoscopy and intubation were recorded for comparison.

Results: Demographic characteristics and baseline vital parameters in both the groups were comparable. Significant differences in mean arterial pressure (MAP) and heart rate (HR) were observed in between the groups during postintubation period.

Conclusions: Combination of intravenous Fentanyl plus Nitroglycerin spray is more effective than NTG alone in attenuating the stress response following laryngoscopy and intubation.
\end{abstract}

Keywords: Endotracheal intubation, Fentanyl, Haemodynemic stabi, Nitroglycerine

\section{INTRODUCTION}

Laryngoscopy and tracheal intubation are mandatory for most patients undergoing operations under general anaesthesia, which invariably is associated with certain cardiovascular changes such as tachycardia, rise in blood pressure and a wide variety of cardiac arrhythmias. ${ }^{1}$ The hemodynamic response to laryngoscopy and intubation was first described by Reid and Brace in 1940. A typical pressor response can leads to an average increase in blood pressure by $40-50 \%$ and heart rate by $20 \%$ and an elevation of both epinephrine and norepinephrine levels.
These effects are generally well tolerated by overall healthy patients but can be lethal to patients with preexisting conditions such as coronary artery disease, recent myocardial infarction, hypertension, geriatric population pre-eclampsia, and cerebrovascular pathology such as tumours, aneurysms or increased intracranial pressure etc., and are at increased risk of morbidity and mortality. ${ }^{2}$

Geriatric and elderly patients which make up an increasingly large percentage of both the inpatient and outpatient hospital population, have an increased 
incidence of coronary artery disease and cerebrovascular disease and elevated baseline blood pressure, making them especially susceptible to swings in blood pressure, and heart rate during laryngoscopy and endotracheal intubation, which is detrimental in patients with limited cardiovascular reserve with the resultant risk of Myocardial Infarction (MI), Stroke, Congestive heart failure or sudden death. ${ }^{3-5}$

The therapeutic armamentarium to counteract the cardiovascular responses to laryngoscopy and tracheal intubation includes a wide variety of drugs, techniques and routes of administration. A wide variety of pharmacological agents like Lignocaine, Fentanyl, Alfentanil, Remifentanil, Nifedipine, Beta-blockers, Gabapentin, Magnesium Sulfate,Verapamil, Nicardipine, Diltiazem etc. have been used to attenuate the hemodynamic responses to laryngoscopy and endotracheal intubation with varying results. ${ }^{6-9}$

Glyceryl Trinitrate (Nitroglycerin or NTG) which is a predominant veno-dilator has been recently introduced as lingual pump spray or pen spray, to attenuate the stress response to laryngoscopy and endotracheal intubation. ${ }^{9}$

Fentanyl citrate, an opioid is a phenylpiperidine of the 4aminopiperidine series structurally related to pethidine and controls both heart rate and blood pressure responses. ${ }^{10,11}$ However, Fentanyl can produce complex respiratory depression and truncal rigidity at higher doses. Administration of NTG alone during preintubation may not be sufficient to completely mediate hemodynamic response due to the tendency of Nitroglycerine to produce tachycardia. ${ }^{12}$

Despite the efficacy demonstrated in previous studies, indepth analysis and ideal dose combination of Fentanyl and Nitroglycerine required to suppress the hemodynamic response to endotracheal intubation has not yet been determined. ${ }^{13-16}$ Therefore, the purpose of this study is to investigate the efficacy of sublingual Nitroglycerine spray alone and sublingual Nitroglycerine spray with intravenous Fentanyl to attenuate the pressor response to laryngoscopy and intubation in normotensive patients.

\section{METHODS}

This was a prospective, randomized, controlled and parallel group clinical study and conducted in 120 patients aged 20-60 years of both sexes belonging to ASA grade I and II undergoing elective non cardiac surgery requiring endotracheal intubation for maintenance of anaesthesia. A written informed consent was taken from all the patients individually.

\section{Sample size}

Based on a pilot study a sample size of 40 per group with type I error of 0.05 and type II error of 0.20 for $25 \%$ difference in MAP between groups was calculated, hence a total of 120 patients were included. Patients belonging to ASA III and above, any emergency operation; patients with other co-morbid illness like diabetes, hypertension, respiratory disease, hepatic or renal derangements; patients on antipsychotic medication, history of allergy to the study drugs, anticipated difficult airway etc. were excluded from the study.

A detailed pre-anaesthetic evaluation including routine investigations was done on all patients and were explained about the anaesthesia technique. All patients were given Tablet Alprazolam $0.5 \mathrm{mg}$, orally on the night before the operation and preoperative fasting for 8 hours were ensured before administering the general anaesthesia. The patients were randomly allocated and divided into three groups of 40 each by closed envelope method. All patients received standard anaesthesia technique with injection Thiopentone sodium $5 \mathrm{mg} / \mathrm{kg}$ and injection Vecuronium Bromide $0.1 \mathrm{mg} / \mathrm{kg}$ as muscle relaxant and maintained with $66.66 \% \mathrm{~N}_{2} \mathrm{O}$ in $\mathrm{O}_{2}$ and Sevoflurane $(0.2-1 \%)$ and Vecuronium top-up doses as necessary.

- Group-1: Control group- Normal saline infusion.

- Group-2: NTG group-NTG sub-lingual spray (0.4 $\mathrm{mg} /$ spray) two min. before induction.

- Group-3: NTG+ intravenous Fentanyl group- inj. Fentanyl $(2 \mu \mathrm{g} / \mathrm{kg}) 5 \mathrm{~min}$ before + NTG sub-lingual spray ( $0.4 \mathrm{mg} /$ spray) $2 \mathrm{~min}$ before induction.

HR, SBP, DBP and MAP were recorded at T0: Baseline (before premedication), $\mathrm{T}$ : Just before intubation, $\mathrm{T} 1$ : 1 min after intubation, T3: $3 \mathrm{~min}$ after intubation, and T5: $5 \mathrm{~min}$ after intubation. Any incidence of hypotension (fall in SBP $>20 \%$ from baseline), hypertension (rise in SBP $>20 \%$ from baseline), bradycardia (fall in HR $>20 \%$ from baseline), tachycardia (rise in HR $>20 \%$ of baseline), arrhythmias, and ST-T changes etc. were noted and treated accordingly.

\section{Statistical analysis}

The data were recorded on predesigned and pretested proforma, and was tabulated and master chart was prepared in Microsoft Excel 2007. Demographic data, Heart Rate (HR), systolic BP, diastolic BP and Mean arterial pressure (MAP) were tabulated as Mean and Standard deviation.

Statistical significance was tested by ANNOVA test with Post hoc analysis, paired student t-test was used for analyses within the group and unpaired Student t-test was used for comparison between the groups and Chi square test with or without Yates' correction wherever applicable.

All analysis was done by using two tailed test, with $\mathrm{P}$ value of less than 0.05 was considered significant and less than 0.001 as highly significant. 


\section{RESULTS}

Demographic characteristics of patients were comparable. No significant difference was observed among the groups $(\mathrm{p}>0.05)$.

\section{Heart rate changes}

Baseline HR values of the patients in all the groups were comparable ( $p$ >0.05). Significant difference was observed in between group 1 and group 2, and in between group 2 and group 3 , following induction.

Rise in heart rate during post-intubation periods were insignificant in between group 1 and group 2 but significant between group 2 and group 3 (Table 2).
Table 1: Demographic profile.

\begin{tabular}{|lllll|}
\hline Category & Group 1 & Group 2 & Group 3 & $\begin{array}{l}\text { P- } \\
\text { Value }\end{array}$ \\
\hline $\begin{array}{l}\text { Age (yrs) } \\
\text { Mean } \pm \text { SD }\end{array}$ & $37.50 \pm 7.90$ & $39.35 \pm 9.77$ & $38.70 \pm 10.33$ & 0.671 \\
\hline $\begin{array}{l}\text { Male } \\
\text { Female }\end{array}$ & $24(60 \%)$ & $18(45 \%)$ & $20(50 \%)$ & 0.393 \\
\hline $\begin{array}{l}\text { ASA I } \\
\text { ASA II }\end{array}$ & $26(65 \%)$ & $22(55 \%)$ & $20(50 \%)$ & \\
\hline $\begin{array}{l}\text { Height } \\
(\mathrm{mtr})\end{array}$ & $14(35 \%)$ & $16(40 \%)$ & $15(37.5 \%)$ & 0.899 \\
Mean \pm SD & $1.51 \pm 0.05$ & $1.51 \pm 0.04$ & $1.52 \pm 0.04$ & 0.588 \\
\hline $\begin{array}{l}\text { Weight } \\
\text { kg) }\end{array}$ & $62.33 \pm 5.56$ & $63.18 \pm 4.16$ & $62.53 \pm 4.60$ & 0.715 \\
Mean \pm SD & & & & \\
\hline $\begin{array}{l}\text { BMI } \\
\text { kg/m }\end{array}$ & $27.30 \pm 2.45$ & $27.63 \pm 1.30$ & $26.95 \pm 1.80$ & 0.260 \\
Mean \pm SD & & & & \\
\hline
\end{tabular}

Table 2: HR- beats/min (Mean \pm SD).

\begin{tabular}{|c|c|c|c|c|c|c|}
\hline \multirow[b]{2}{*}{ Time } & \multicolumn{3}{|l|}{ Groups } & \multicolumn{3}{|l|}{ P-Value } \\
\hline & Group 1 & Group 2 & Group 3 & $\begin{array}{l}\text { Group } 1 \text { vs } \\
\text { Group } 2\end{array}$ & $\begin{array}{l}\text { Group } 1 \text { vs } \\
\text { Group } 3\end{array}$ & $\begin{array}{l}\text { Group } 2 \text { vs } \\
\text { Group } 3\end{array}$ \\
\hline T0 & $92.23 \pm 6.76$ & $91.15 \pm 4.15$ & $89.83 \pm 6.81$ & 0.7036 & 0.1814 & 0.5922 \\
\hline $\mathrm{T}$ & $90.38 \pm 10.92$ & $95.93 * \pm 8.61$ & $88.23 \pm 10.27$ & 0.0378 & 0.6014 & 0.0022 \\
\hline $\mathrm{T} 1$ & $\begin{array}{l}115.75 \pm 5.99 * * \\
\text { (25.5\% rise) }\end{array}$ & $\begin{array}{l}117.68 \pm 8.81 * * \\
\text { (29.1\% rise) }\end{array}$ & $91.10 \pm 15.85$ & 0.7143 & $<0.001$ & $<0.001$ \\
\hline $\mathrm{T} 3$ & $105.33 \pm 8.82 * *$ & $107.25 \pm 5.18 * *$ & $86.38 \pm 12.22$ & 0.6204 & $<0.001$ & $<0.001$ \\
\hline T5 & $101.20 \pm 9.20 * *$ & $104.53 \pm 8.40 * *$ & $87.68 \pm 11.98$ & 0.2983 & $<0.001$ & $<0.001$ \\
\hline
\end{tabular}

$* \mathrm{P}<0.05$, significant, $* * \mathrm{P}<0.001$, highly significant rise in $\mathrm{HR}$ as compared to baseline within the group

Table 3: MAP (mmhg)-(Mean \pm SD).

\begin{tabular}{|lllllll|}
\hline & Groups & P-Value & Group1 vs & $\begin{array}{l}\text { Group1 vs } \\
\text { Group3 }\end{array}$ & $\begin{array}{l}\text { Group2 vs } \\
\text { Group3 }\end{array}$ \\
\hline Time & Group1 & Group2 & Group3 & $\begin{array}{l}\text { Group2 } \\
\text { Group2 }\end{array}$ & 0.5257 & 0.1637 \\
\hline T0 & $90.80 \pm 10.8$ & $92.4 \pm 8.37$ & $88.48 \pm 9.38$ & 0.7356 & 0.0008 & 0.8421 \\
\hline T & $87.07 \pm 9.24$ & $\begin{array}{l}81.63 \pm 6.08 \\
\#(11.65 \% \text { fall })\end{array}$ & $\begin{array}{l}80.68 \pm 7.14 \\
\#(8.81 \% \text { fall })\end{array}$ & 0.005 & $<$ & 0.008 \\
\hline T1 & $\begin{array}{l}113.72 \pm 4.80 * * \\
(25.24 \% \text { rise })\end{array}$ & $95.60 \pm 11.22$ & $90.39 \pm 5.17$ & $<0.001$ & $<0.001$ & 0.005 \\
\hline T3 & $109.32 \pm 3.37$ & $93.84 \pm 9.04$ & $88.002 \pm 6.52$ & $<0.001$ & $<0.001$ & $<.0003$ \\
\hline T5 & $105.17 \pm 3.58$ & $91.62 \pm 7.98$ & $86.30 \pm 5.54$ & $<0.001$ & $<0.001$ & 0.001 \\
\hline
\end{tabular}

$*(\mathrm{P}<0.05)-$ Significant, $* *(\mathrm{P}<0.001)$ - highly Significant rise from baseline; \# $(\mathrm{P}<0.05)$ Significant fall from baseline, MAP $=$ Mean arterial pressure, $\mathrm{SD}=$ Standard deviation

\section{Changes in MAP}

Baseline values of MAP of all the groups were comparable ( $p$ >0.05). Significant differences were observed between group 1 and group and between group 2 and group 3 ( $\mathrm{p}<0.001)$ (Table 3$)$.

\section{Adverse effects}

Adverse effects like tachycardia, arrhythmia, hypertension was mostly seen in group 1 and group 2 in comparison to group 3. Patients in group 3 were observed to be haemodynemically more stable than the other two groups.

\section{DISCUSSION}

Intubation of the trachea alters respiratory and cardiovascular physiology both via reflex responses and by the physical presence of endotracheal tube. The usual circulatory responses to laryngeal and tracheal stimulation in anaesthetized subject are tachycardia and rise in arterial pressure. ${ }^{3,6,7}$ 


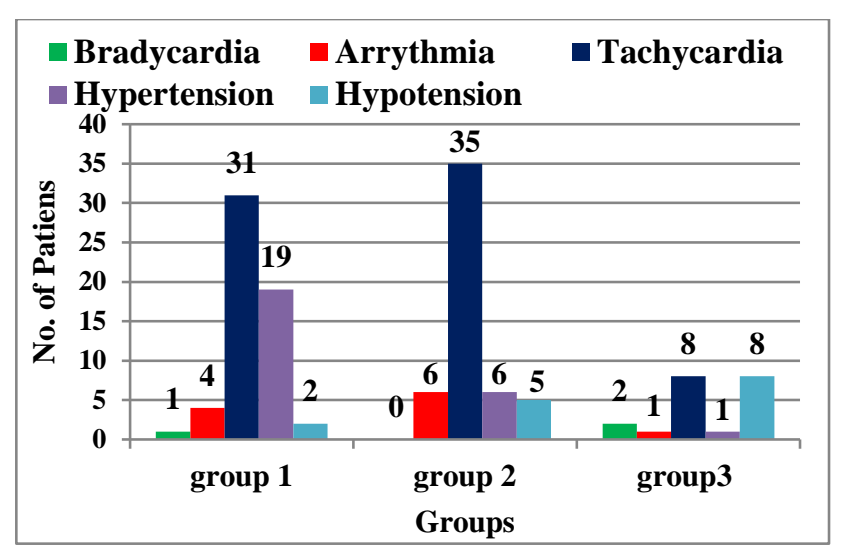

Figure 1: Adverse effects in the three groups.

Various studies have been performed on hemodynamic changes to laryngoscopy and intubation. Prys-Roberts et al, King et al etc., studied the reflex cardiovascular response such as hypertension and tachycardia to direct laryngoscopy and tracheal intubation during general anaesthesia. ${ }^{1,4}$

However these response usually does not present a problem for most the young and healthy patients but patients with cardiovascular or cerebrovascular disease, geriatric patients may be at increased risk of morbidity and mortality from the tachycardia and hypertension resulting from the stress. ${ }^{3,4}$

A varieties of pharmacological agents have been used to attenuate the hemodynamic response to laryngoscopy and intubation such as deep general anaesthesia, topical anaesthesia, Lignocaine, Fentanyl, Alfentanil, Remifentanil, Nifedipine, beta-blockers, Gabapentin, Magnesium sulfate, Verapamil, Nicardipine, Diltiazem with variable success rate. ${ }^{5}$

Nitroglycerin (Glyceryl trinitrate or NTG) relaxes vascular smooth muscles with venous dilation predominantly over arterial dilation. NTG had been administered in different doses and through different approaches like intranasal, topically or parenterally as a bolus or infusion to attenuate hemodynamic responses during laryngoscopy and intubation. ${ }^{19}$ Kumari I et al used sublingual Nitroglycerin in two doses $(0.4 \mathrm{mg}$ and $0.8 \mathrm{mg})$ Kamra $\mathrm{S}$ et al used 2\% topical Nitroglycerin ointment equivalent to $30 \mathrm{mg}$ Nitroglycerin. ${ }^{13,14}$ Fassoulaki A and Kaniaris P used Nitroglycerin intranasally in a dose of 60 mg. ${ }^{15}$ Anant and Waghray used intranasal NTG spray for attenuation of pressor response to intubation. ${ }^{16}$ All these studies cited above revealed conflicting results.

Fentanyl is an opioid commonly used as an adjunct to anaesthesia which increases the depth of anesthesia and decreases sympathetic discharge thereby causing suppression of hemodynamic response to laryngoscopy and intubation. Large dose of Fentanyl often leads to muscular rigidity, bradycardia, respiratory depression, post-operative nausea, and vomiting. ${ }^{16}$
In our study, we planned to compare the effect of Nitroglycerin sublingual spray alone in one group and the combination of Nitroglycerin sublingual spray plus intravenous Fentanyl in the other group in attenuation of intubation response. We administered Nitroglycerin sublingual spray (single spray) which delivered 400 microgram NTG, 2 minute before intubation in one group and intravenous Fentanyl $2 \mu \mathrm{g} / \mathrm{kg} 5$ minutes before followed by sublingual Nitroglycerin spray (1 spray) 2 minutes before intubation in the other group. 40 patients in each group of ASA grade 1 and 2 were chosen for the study.

The three groups of our study were comparable as regards of age and sex distributions (Table 1). The premedication technique, intubation and extubation techniques were similar in all the three groups. Hypoxia and hypercarbia were avoided. $\mathrm{EtCO}_{2}$ was maintained between 30-40 mm $\mathrm{Hg}$ and saturation maintained above 97\%. Continuous lead II ECG monitoring was done. The changes in haemodynamic parameters following laryngoscopy and intubation were measured and compared with pre-induction values, which were taken to be baseline. Both within the group and intergroup comparisons were done. The results and observations that were obtained in the present study are being compared in the light of other investigators.

\section{Haemodynamic variables}

The mean baseline HR SBP, DBP and MAP in the three groups were comparable.

In group 2 (NTG group), heart rate continued to rise till 1 minute after intubation and then gradually came down but it did not reach the baseline value. Rise of heart rate was maximum at 1 minute after intubation $(29.1 \%)$ which was statistically highly significant $(\mathrm{P}<0.001)$. Significance difference was found in comparison to group-1 just before intubation $(\mathrm{p}<0.05)$. There was statistically no significant difference in between group 1 and group 2 at any point of time interval following intubation. Our finding was similar to the study conducted by. Vyas $A B$ et al who conducted a study in 60 patients who received three different doses of intranasal Nitroglycerin (Group

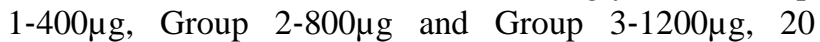
patients in each group) five minutes before induction. ${ }^{17}$ Kumari I et al also found similar observations in 90 adult ASA I and II patients using sublingual spray of NTG (1 spray and 2 spray one minute before intubation) in attenuation of pressor response to intubation. ${ }^{13}$ Studies conducted by Mikawa $\mathrm{K}$ et al, Grover VK et al and Fassoulaki A and Kaniaris $\mathrm{P}$ have also documented that NTG does not attenuate the rise in heart rate following laryngoscopy and endotracheal intubation which can be attributed to reflex tachycardia produced by vasodilatation. $^{15,18,19}$

When intravenous Fentanyl was used along with Nitroglycerin sublingual spray in group $3(\mathrm{~F}+\mathrm{NTG})$, it 
resulted in more optimal control of tachycardia produced by laryngoscopy and intubation. In the group 3, baseline heart rate came down just before intubation and then rose to maximum at 1 minute after intubation followed by gradual fall at $3^{\text {rd }}$ and $5^{\text {th }}$ minutes bellow the baseline value. Significant differences were observed in comparison to other two groups $(p<0.001)$ during each time interval following intubation. Our results coincide with a study conducted by Gupta and Tank et al, Parida S et al who used Fentanyl $2 \mu \mathrm{g} / \mathrm{kg}$ intravenously slowly 3 min before induction of anesthesia to attenuate the pressor response to laryngoscopy and intubation. ${ }^{11,20}$ Withington PS et al found that the heart rate was consistently higher but not statistically significant after NTG infusion during Fentanyl, thiopentone, pancuronium anaesthesia in coronary artery bypass graft surgery. ${ }^{21}$ Ebert JP et al reported Fentanyl intravenously decreased heart rate below baseline and maintained it there. ${ }^{22}$

\section{Mean blood pressure}

Maximum rise in mean blood pressure was seen at 1 minute post-intubation period in all the groups. Significant attenuation of mean blood pressure was observed in the both group 2 (NTG) and group 3 $(\mathrm{F}+\mathrm{NTG})$ during the post-intubation period in comparison to control group (group 1). However significant difference was found in between group 2 and group 3. A Stable haemodynamic with significant attenuation of SBP, DBP, MBP and heart rate was found in the group 3 following endotracheal intubation in comparison to group 1 and group 2. In studies conducted by Vyas AB et al, Kumari I et al, Kamra S et al, Grover VK et al, Mahajan $\mathrm{RP}$ et al etc. also found similar results coinciding our study. ${ }^{13,14,17,19,23}$

Fusciardi $\mathbf{J}$ et al concluded that addition of Nitroglycerin by infusion to low-dose Fentanyl anesthesia produced no significant change in MPB, heart rate, cardiac index, or PCWP and is an attractive method for induction as well as decreasing the incidence of myocardial ischemia associated with laryngoscopy and intubation in patients with stable angina undergoing short-duration noncardiac surgery. ${ }^{12}$

\section{Adverse effects}

Adverse effects are shown in Figure 1. Bradycardia was treated with Inj. Atropine and hypotension with mephentermine. Out of 120 patients $11(9.16 \%)$ patients (4 in Group 1, 6 in Group 2, and 1 in Group 3) had rhythm changes in the form of ventricular bigeminy, atrial ectopics or ventricular premature beats following intubation. Ko SH et al reported $11 \%$ incidence of rhythm disturbance during laryngoscopy and intubation in their study. ${ }^{24}$ No ST-changes were observed. None of the cases had any bronchospasm or chest wall rigidity.

\section{Limitations}

Present study was done in a small group of 40 patients each in the groups. All patients were belonging to ASA I and II. Patients with comorbid conditions like coronary artery disease, hypertension and diabetes, etc. were excluded from the study. Another major limitation of our study is that stress mediators were not measured during the study period which would have given the measurement of effect of study drugs on stress response to laryngoscopy and tracheal intubation. In addition, influence of age of patient on pressor response to laryngoscopy and intubation or role of preoperative antihypertensive medications were not evaluated in our study. Hence further research can be done to study the effects of age and antihypertensive medications on laryngoscopy and endotracheal intubation can be planned.

\section{CONCLUSION}

Combination of intravenous Fentanyl plus Nitroglycerin spray is more effective than NTG alone in attenuating the haemodynamic response following laryngoscopy and intubation without any major side effects in otherwise healthy patients undergoing elective surgeries under general anaesthesia. However, more studies with larger population is required to come to a final conclusion.

\section{Funding: No funding sources \\ Conflict of interest: None declared}

Ethical approval: The study was approved by the Institutional Ethics Committee

\section{REFERENCES}

1. King BD, Harris LC, Breifenstein FE. Reflex circulatory responses to direct laryngoscopy and tracheal intubation performed during general anesthesia. Anesthesiology. 1951;12:55-66.

2. Reid LC, Brace DE. Irritation of the respiratory tract and its reflex effect upon heart. Surg Gynaecol Obstet. 1940;70:157-62S.

3. Hagberg CA. Artime CA. Airway Management in Adults: Miller's Anesthesia. Miller RD, Cohen NH, Erikson LI, Fleisher LA, Wiener-Kronish JP, Young WL. $8^{\text {th }}$ Ed.; 2015,1:1647-1680 .

4. Prys-Roberts C, Greene LT, Meloche R, Foex P. Studies of anaesthesia in relation to hypertension. II. Haemodynamic consequences of induction and endotracheal intubation. Br J Anaesth. 1971;43:53147.

5. Kovac AL. Controlling the hemodynamic response to laryngoscopy and endotracheal intubation. J Clin Anesth. 1996;8:63-79.

6. Fox EJ, Sklar GS, Hill CH, Villanueva R, King BD. Complications related to the pressure response to endotracheal intubation. Anaesthesiology. 1977;47:524-5. 
7. Dahlgren N, Messeter K. Treatment of stress response to laryngoscopy and intubation with fentanyl. Anaesthesia. 1981;36:1022-6.

8. Kumari I, Pathania VS. A prospective randomised double blind placebo controlled trial of oral gabapentin in attenuation of haemodynamic responses during laryngoscopy and tracheal intubation. J Anaesth Clin Pharmacol. 2009;25:43943.

9. Kaplan JA, Dunbar RW, Jones EL. Nitroglycerin infusion during coronary-artery surgery. Anesthesiology. 1976;45:14-21.

10. Ogurlu UB, Erdal MC, Aydin ON. Effects of esmolol, lidocaine and fentanyl on haemodynamic responses to endotracheal intubation: A comparative study. Clin Drug Investig. 2007;27:269-77.

11. Gupta S, Tank P. A comparative study of efficacy of esmolol and fentanyl for pressure attenuation during laryngoscopy and endotracheal intubation. Saudi J Anaesth. 2011 Jan-Mar;5(1):2-8.

12. Fusciardi J, Godet G, Bernard JM, Bertrand M, Kieffer E, Viars P. Roles of Fentanyl and Nitroglycerin In Prevention Of Myocardial Ischemia Associated With Laryngoscopy And Tracheal Intubation In Patients Undergoing Operations Of Short Duration. Anesth Analg. 1986 Jun;65(6):61724.

13. Kumari I, Naithani U, Dadheech VK, Pradeep DS, Meena K, Verma D. Attenuation of pressor response following intubation: Efficacy of nitro-glycerine lingual spray. Journal of Anaesthesiology, Clinical Pharmacology. 2016;32(1):69-73.

14. Kamra S, Wig J, Sapru RP. Topical Nitroglycerin a Safeguard against Pressor Responses to Tracheal Inlubation. Anaesthesia. 1986;41:1087-91.

15. Fassoulaki A, Kaniaris P. Intranasal administration of nitroglycerine attenuates the pressor response to laryngoscopy and intubation of the trachea. $\mathrm{Br} \mathrm{J}$ Anaesth. 1983;55:49-52.

16. Anant S, Waghray M. Hypertensive response to laryngoscopy and intubation: prevention by intranasal nitroglycerine; Journal of Anaesthesiology Clinical Pharmacology. 1991 Apr;7(2):111-4.

17. Vyas AB, Chadha IA, Nambiar PM, Bhat VT, Chavada DD, Sorathiya PC. Comparison of different doses of intranasal nitroglycerine in attenuation of pressor response to laryngoscopy and intubation. Anesthesia, Essays and Researches. 2014 Jan;8(1):59-62.

18. Mikawa K, Hasegawa M, Suzuki T, Maekawa N, Kaetsu H, Goto R, et al. Attenuation of hypertensive response to tracheal intubation with nitroglycerin. J Clin Anesth. 1992;4:367-71.

19. Grover VK, Sharma S, Mahajan RP, Singh H. Intranasal nitroglycerine attenuates pressor response to tracheal intubation in beta-blocker treated hypertensive patients. Anaesthesia. 1987 Aug 1;42(8):884-7.

20. Parida S, Ashraf NC, Mathew JS, Mishra SK, Badhe AS. Attenuation of the haemodynamic responses to tracheal intubation with gabapentin, fentanyl and a combination of both: A randomised controlled trial. Indian J Anaesth. 2015;59:306-11.

21. Withington PS, Durcan JJ, Weir I, Innis R, Savage T. Haemodynamic and metabolic effects of prophylactic nitroglycerin infusion in the immediate period following coronary artery bypass grafting. European heart journal. 1988 Jan 1;9(suppl A):187-93.

22. Ebert JP, Pearson JD, Gelman S, Harris C, Bradley EL. Circulatory responses to laryngoscopy: the comparative effects of placebo, fentanyl and esmolol. Canadian Journal of Anaesthesia. 1989 May $1 ; 36(3): 301-6$.

23. Mahajan RP, Ramachandran R, Saxena N. Topical nitroglycerin prevents the pressor response to tracheal intubation and sternotomy in patients undergoing coronary artery bypass graft surgery. Anaesthesia. 1993;48:297-300.

24. Ko SH, Kim DC, Han YJ, Song HS. Small-dose fentanyl: optimal time of injection for blunting the circulatory responses to tracheal intubation. Anesthesia and Analgesia. 1998 Mar 1;86(3):658-61.

Cite this article as: Pegu B, Dutta S, Pathak DG, Deori KC. Attenuation of stress response to laryngoscopy and intubation: sublingual nitroglycerin spray vs intravenous fentanyl and sublingual nitroglycerin spray. Int J Basic Clin Pharmacol 2017;6:1414-9. 